\title{
Contribution of microsatellites markers in the clarification of the origin, genetic risk factors, and implications for conservation of Tunisian native sheep breeds
}

\author{
Y. Ben Sassi-Zaidy ${ }^{1,2}$, F. Maretto ${ }^{2}$, F. Charfi-Cheikhrouha' ${ }^{1}$, A. Mohamed-Brahmi ${ }^{3}$ \\ and M. Cassandro ${ }^{2}$ \\ 1UR 11ES11 Bio-Ecologie et Systématique Evolutive, Faculté des Sciences de Tunis, \\ Université de Tunis El Manar, Tunis, Tunisie \\ 2Department of Agronomy, Food, Natural Resources, Animals and Environment, \\ University of Padova, Legnaro, Italy \\ ${ }^{3}$ Laboratoire d'Appui à la Durabilité des Systèmes de Production Agricole dans la \\ Région du Nord-Ouest, Département de la Production Animale, Ecole Supérieure \\ d'Agriculture du Kef Boulifa, Le Kef, Tunisie \\ Corresponding author: Y. Ben Sassi-Zaidy \\ E-mail: bensassizaidyyousra@yahoo.fr \\ Genet. Mol. Res. 15 (1): gmr.15017059 \\ Received September 1, 2015 \\ Accepted November 19, 2015 \\ Published March 11, 2016 \\ DOI http://dx.doi.org/10.4238/gmr.15017059
}

ABSTRACT. The genetic diversity and genetic relationship of the two main groups of African sheep, thin-tailed and fat-tailed sheep, represented by the indigenous Tunisian sheep breeds "Barbarine" (BAR, fat-tailed) and "Queue Fine de l'Ouest" (QFO, thin-tailed) were investigated. The genotypes of 110 animals belonging to these two breeds and their crossbreed (CRO) were assessed using 17 microsatellite markers. The results showed high levels of genetic diversity and a total of 256 alleles were identified in the whole population. The mean values of observed and expected heterozygosity were 0.719 and 0.789 , respectively, and the mean allelic richness estimate was 10.89 . The average $F_{\text {IS }}(0.112)$ and $F_{\text {IT }}(0.118)$ 
values over all loci indicated a notable level of inbreeding within the whole population. However, the $F_{\text {ST }}$ value $(0.007)$ showed a low level of genetic differentiation between these two native breeds. The high level of both gene flow and molecular coancestry coefficient detected between the two breeds and their CRO revealed an old miscegenation between the BAR and QFO breeds. The clustering analysis performed with the STRUCTURE software confirmed gene flow between these two breeds. Results arising from this study provide evidence regarding the genetic structure and variability of the two main local sheep breeds, and the implications of their actual management, which indicates the need for an urgent conservation strategy in order to prevent significant gene flow and preserve the remaining breed specificity for future generations.

Key words: Tunisian indigenous sheep; Microsatellite markers; Genetic variability; Population structure

\section{INTRODUCTION}

In developing countries, livestock genetic resources greatly contribute to sustainable development and to livelihood security and food safety by reducing hunger and poverty. In Tunisia, sheep is the most important livestock species, representing $77 \%$ of the total number of reared animals. Sheep production in Tunisia holds an important place in the economy, contributing to almost $42 \%$ of total red meat production (OEP, 2009). The sheep breeding sector is largely dominated (94\%) by indigenous meat breeds: the "Barbarine" (BAR) and the "Queue Fine de l'Ouest" (QFO). According to the morphology of the tail and their geographic origins, these two sheep have been classified as belonging to two different African sheep groups: BAR to the fattailed group and QFO to the thin-tailed group (Muigai and Hanotte, 2013).

In Tunisia, the BAR and the QFO are classified as two different breeds that may have different ancestral origins. BAR is the most important native breed, representing $64 \%$ of the total sheep reared in Tunisia (Agriculture Ministry, 2006). This breed is found in large parts of North Africa and it is the dominant breed in Tunisia and Libya, and is also widespread in Algeria. The BAR breed is thought to be derived from the Egyptian fat-tailed sheep (Ben Salem et al., 2011; Muigai and Hanotte, 2013). Originating from the Asiatic steppes (Mason, 1967), the BAR breed is a medium sized meat-type sheep, characterized essentially by its bi-lobed fat tail resulting from the accumulation of fat reserves on each side of the coccygeal vertebra. This fat is considered to be an effective tool for resistance to severe climate conditions. The BAR breed has developed tolerance to both warm and cold climates, a remarkable mothering ability, resistance to parasites, and the ability to use a wide range of low quality feed resources (Ben Salem et al., 2011). Furthermore, BAR had an important socio-cultural role as the dominant sacrificial animal, and consumers still prefer BAR meat, mainly for its tenderness, flavor, and smell (Bedhiaf-Romdhani et al., 2008). QFO is a thin-tailed sheep, and represents $30 \%$ of the total sheep breeds reared in Tunisia (Agriculture Ministry, 2006). This meat-type breed, derived from the Algerian Ouled Djellal breed, is adapted to harsh dry conditions but not as well adapted to warmth as the BAR breed. The QFO breed has been gaining importance over the BAR breed during the last few decades; the proportion of BAR ewes has decreased from approximately $85 \%$ in the seventies to only $60.3 \%$ in 2011 (Agriculture Ministry, 2012), while QFO ewes have increased from 9 to $34.6 \%$ over the same period. 
The BAR and the QFO breeds assume a national importance as they will continue to be the main meat providers to Tunisian commercial channels, and they significantly contribute to meeting the objectives of the national strategy aimed at red meat self-sufficiency. Crossbreeding between these two breeds is currently being practiced by breeders in central and northern Tunisia, creating a new population named "Chirki" (CRO). Avoiding the large BAR fat tail, which represents an obstacle to free mating, and the difficulties encountered by butchers in selling this fat, which can reach $15 \%$ of the carcass weight, are the reasons for these crossbreeding trends, as mentioned by Bedhiaf-Romdhani et al. (2008). Identification of the genetic relationships and the patterns of gene flow among the BAR and QFO breeds could provide important clarification, especially regarding the extent of their crossbreeding. Microsatellite markers are widely used for genetic analyses in livestock and are of fundamental importance in supporting the establishment of conservation programs for the genetic resources. In this study, microsatellites may improve the understanding of the present population structure of these native Tunisian sheep breeds and could help to clarify the results of this crossbreeding. Hence, the aim of the present study is to assess the level of genetic differentiation and gene flow between BAR, QFO, and their crossbreed (CRO), using microsatellite markers to support the decision-making process in crossbreeding activities.

\section{MATERIAL AND METHODS}

\section{Animal sampling and microsatellite analysis}

A total of 110 individual blood samples were collected from unrelated animals belonging to BAR, QFO, and CRO individuals from different agroecological zones. Because of the absence of herd books, the animals were chosen as three unrelated animals from each farm or small flock based on information provided by the farmer to avoid sampling of closely related individuals. DNA extraction was carried out from whole blood using the Wizard Genomic DNA Extraction kit (Promega, USA) following the manufacturer protocol. A panel of 17 microsatellite markers (Table 1) was established, including some markers from the ISAG/FAO recommended microsatellite markers (FAO, 2011) and others from previous studies (Baumung et al., 2006; Dalvit et al., 2009; Ben Sassi-Zaidy et al., 2014a). Genotypes for all 17 microsatellite markers were identified as described in Ben Sassi-Zaidy et al. (2014b).

\section{Statistical analysis}

The number of alleles per locus $\left(N_{\mathrm{A}}\right)$, allelic frequencies, observed $\left(H_{\mathrm{O}}\right)$ and expected $\left(H_{E}\right)$ heterozygosity, and gene flow $\left(N_{m}\right)$ were calculated using GENETIX version 4.05.2 (Belkhir et al., 1996-2004). The number of private alleles (PA) in the different breeds was counted using the CONVERT software (Glaubitz, 2004). Exact tests for deviations from Hardy-Weinberg Equilibrium (HWE) were applied using GENEPOP version 4.3 (Raymond and Rousset, 1995). The MSA software (Dieringer and Schlötterer, 2003) was used to calculate allelic richness (AR, the mean number of alleles per locus corrected by sample size), and Wright's fixation indices $\left(F_{\mathrm{IS}}\right.$, $F_{\mathrm{IT}}$, and $F_{\mathrm{ST}}$; Weir and Cockerham, 1984). Polymorphism information content (PIC) and relatedness among individuals estimated by measuring within-breed molecular coancestry $\left(f_{\mathrm{ij}}\right)$ were measured using Molkin 3.0 (Gutiérrez et al., 2005). Nei's (1978) genetic distance $\left(D_{\mathrm{A}}\right)$ among populations was estimated and a neighbor-joining (NJ) tree was constructed using the PHYLIP package (Felsenstein, 1989). Bootstraps of 1000 replicates were performed to test the robustness of the 
tree topology. The dendrogram was depicted using MEGA 5 (Tamura et al., 2011). Moreover, a factorial correspondence analysis was performed based on individual multilocus genotypes using GENETIX version 4.03 (Belkhir et al., 1996-2004). The analysis of molecular variance (AMOVA) was performed by the ARLEQUIN software (Excoffier et al., 2005) using the codominant allelic distance matrix with 1000 permutations. To analyze the population structure and to detect the most likely number of clusters $(\mathrm{K})$ in the dataset, the STRUCTURE version 2.3.4 software (Pritchard et al., 2000) was used. To choose the appropriate number of inferred clusters to model the data, 50 independent runs were performed for each $\mathrm{K}(2<\mathrm{K}<7)$. All analyses used a burn-in period of 30,000 and 150,000 iterations for data collection. The optimum number of clusters fitting the data was established by plotting $\mathrm{Ln} \operatorname{Pr}(\mathrm{X} \mid \mathrm{K})$ over the 50 independent runs for each $\mathrm{K}$, as suggested by Pritchard et al. (2000). The output obtained was used directly as input data in the cluster visualization program DISTRUCT (Rosenberg, 2004).

\section{RESULTS AND DISCUSSION}

A total of 256 alleles were detected across the 17 microsatellite loci assessed in the 110 genotyped animals and all markers were highly informative, having PIC values $>0.5$, confirming their usefulness in genetic diversity studies. Descriptive statistics on the variability of the investigated loci are reported in Table 1. The highest number of alleles was found at locus OarCP49 (26) and the lowest at locus OarAE129 (7). Mean $N_{\mathrm{A}}$ was $15.06 \pm 5.02$, and the mean AR was 11.28 \pm 3.17. The mean PIC across all loci was $0.791 \pm 0.091$, ranging from 0.546 (OarAE129) to 0.905 (OarCP49). These values are comparable to those recently recorded by Ben Sassi-Zaidy et al. $(2014 a, b)$ in the first investigation of Tunisian sheep and higher than those estimated in the Zulu South African sheep (Kunene et al., 2014) and in the Kenyan sheep populations (Mukhongo et al., 2014). In the overall population, the homozygote excess $\left(F_{\mathrm{IT}}\right)$ of $0.118 \pm 0.091$ was mainly due to a significant homozygote excess within breeds $\left(F_{\mathrm{IS}}=0.112 \pm 0.091\right)$ rather than genetic differentiation among them since the $F_{\mathrm{ST}}$ index was limited to $0.007 \pm 0.008(\mathrm{P}<0.001)$.

Table 1. Characteristics of the microsatellite loci used to genotype individuals from three Tunisian sheep breeds: Barbarine, Queue Fine de l'Ouest, and a crossbred population Chirki.

\begin{tabular}{l|c|c|c|c|c|c|c|c}
\hline Locus & Chr & Fragment size $(\mathrm{bp})$ & $N_{\mathrm{A}}$ & AR & PIC & $F_{\mathrm{IS}}$ & $F_{\mathrm{IT}}$ & $F_{\mathrm{ST}}$ \\
\hline Inra023 & 1 & $195-221$ & 13 & 11.62 & 0.882 & 0.013 & 0.013 & 0.000 \\
\hline Inra063 & 14 & $168-206$ & 19 & 13.29 & 0.839 & 0.142 & 0.153 & 0.012 \\
\hline OarCP49 & 17 & $71-137$ & 26 & 18.86 & 0.905 & 0.076 & 0.080 & 0.004 \\
\hline OarFCB304 & 19 & $145-219$ & 19 & 13.64 & 0.820 & 0.117 & 0.131 & 0.016 \\
\hline OarFCB20 & 2 & $87-117$ & 15 & 11.26 & 0.863 & 0.083 & 0.091 & 0.009 \\
\hline MAF65 & 15 & $119-139$ & 12 & 8.830 & 0.735 & 0.032 & 0.048 & 0.018 \\
\hline ILST087 & 6 & $142-178$ & 22 & 15.40 & 0.879 & 0.206 & 0.205 & -0.002 \\
\hline OarAE119 & 19 & $141-183$ & 11 & 9.390 & 0.759 & 0.043 & 0.047 & 0.004 \\
\hline MCM527 & 5 & $164-188$ & 12 & 9.610 & 0.804 & 0.191 & 0.206 & 0.020 \\
\hline MAF214 & 16 & $176-262$ & 14 & 8.510 & 0.656 & 0.319 & 0.318 & 0.001 \\
\hline OarAE129 & 5 & $135-163$ & 7 & 6.180 & 0.546 & 0.256 & 0.265 & 0.011 \\
\hline OarCP34 & 3 & $101-117$ & 8 & 6.460 & 0.737 & -0.002 & 0.007 & 0.009 \\
\hline OarAE54 & 25 & $124-148$ & 13 & 10.84 & 0.730 & 0.037 & 0.035 & -0.001 \\
\hline TGLA53 & 12 & $139-167$ & 11 & 10.16 & 0.820 & 0.122 & 0.136 & 0.016 \\
\hline URB058 & 13 & $159-211$ & 18 & 13.31 & 0.801 & 0.069 & 0.070 & 0.000 \\
\hline CSRD247 & 14 & $214-262$ & 19 & 12.30 & 0.809 & 0.086 & 0.082 & -0.003 \\
\hline HSC & 20 & $260-296$ & 17 & 12.11 & 0.858 & 0.042 & 0.066 & 0.026 \\
\hline Mean & - & - & 15.06 & 11.28 & 0.791 & 0.112 & 0.118 & 0.007 \\
\hline S.D. & - & - & 5.02 & 3.170 & 0.091 & 0.091 & 0.091 & 0.008 \\
\hline
\end{tabular}

Chr = chromosome; $N_{\mathrm{A}}=$ number of alleles; $\mathrm{AR}=$ allelic richness; $\mathrm{PIC}=$ polymorphic information component; $F_{\mathrm{IS}}, F_{\mathrm{IT}}$, and $F_{\mathrm{ST}}=$ fixation indices according to Weir and Cockerham (1984); S.D. = standard deviation. 
The genetic variability of the two breeds and their crossbreed was initially studied in terms of $N_{\mathrm{A}}, \mathrm{PA}$, and AR, as shown in Table 2. The BAR breed had the highest $N_{\mathrm{A}}$, while CRO had the lowest. A total of 70 (27.34\%) PA were detected among the studied groups. However, only 16 PA were present in frequencies of $>0.025$. The highest number of PA (35) was found in the BAR breed, with 9 of them were present at a frequency $>0.025$. In this breed, the marker (OarAE129) exhibited only one PA at a frequency of 0.05 , while three and four PA at a frequency $>0.025$ were found in QFO and CRO, respectively.

Table 2. Genetic variability of two Tunisian sheep breeds, Barbarine (BAR) and Queue Fine de l'Ouest (QFO), and their crossbred population, Chirki (CRO).

\begin{tabular}{|c|c|c|c|c|c|c|c|c|c|c|}
\hline \multirow[b]{2}{*}{ Breed } & \multirow[t]{2}{*}{$\mathrm{N}$} & \multirow[t]{2}{*}{$N_{A}$} & \multicolumn{2}{|c|}{ PA } & \multirow[t]{2}{*}{$\mathrm{AR} \pm \mathrm{SD}$} & \multirow[t]{2}{*}{$H_{\circ} \pm S D$} & \multirow[t]{2}{*}{$H_{\mathrm{E}} \pm \mathrm{SD}$} & \multirow[t]{2}{*}{$F_{\text {IS }} \pm \mathrm{SD}$} & \multirow[t]{2}{*}{ HWE } & \multirow[t]{2}{*}{$f_{i j} \pm S D$} \\
\hline & & & $\mathrm{t}$ & $f$ & & & & & & \\
\hline BAR & 50 & 12.18 & 35 & 9 & $10.88 \pm 3.73$ & $0.739 \pm 0.116$ & $0.796 \pm 0.093$ & $0.082 \pm 0.146$ & $1^{* \star *}$ & $0.20 \pm 0.02$ \\
\hline QFO & 30 & 11.35 & 19 & 3 & $11.29 \pm 3.24$ & $0.736 \pm 0.145$ & $0.812 \pm 0.068$ & $0.110 \pm 0.117$ & $1^{* * *}$ & $0.18 \pm 0.02$ \\
\hline CRO & 30 & 10.65 & 16 & 4 & $10.50 \pm 3.26$ & $0.682 \pm 0.168$ & $0.787 \pm 0.078$ & $0.150 \pm 0.144$ & $3^{\star * *}$ & $0.20 \pm 0.02$ \\
\hline
\end{tabular}

$\mathrm{N}=$ number of analyzed samples; $N_{\mathrm{A}}=$ mean number of alleles; $\mathrm{PA}=$ private alleles $(\mathrm{t}=$ total number of $\mathrm{PA} ; \mathrm{f}=\mathrm{number}$ of PA with frequency >0.025); $\mathrm{AR}=$ allelic richness; $H_{\mathrm{O}}=$ observed heterozygosity; $H_{\mathrm{E}}=$ expected heterozygosity; $F_{\text {IS }}=$ within-population heterozygote deficiency; HWE = number of loci deviating from Hardy-Weinberg equilibrium; $\mathrm{f}_{\mathrm{ij}}=$ within-population molecular coancestry coefficient. ${ }^{* * *} \mathrm{P}<0.001$. Lowest heterozygosity and greatest inbreeding coefficient $\left(F_{\mathrm{IS}}\right)$ values exhibited by CRO population are shown in bold font.

In general, the analyzed populations showed reasonably high allelic richness and heterozygosity values compared to some African (Soma et al., 2012; Kunene et al., 2014; Mukhongo et al., 2014), European (Salamon et al., 2014), Asian (Al-Barzinji et al., 2011; Blackburn et al., 2011b), and American (Blackburn, et al., 2011a; Souza et al., 2012; Ferreira et al., 2014) sheep breeds. The lowest values of AR and heterozygosity were observed in the crossbred population in which $H_{\mathrm{O}}$ was notably lower than the $H_{\mathrm{E}}$ (Table 2). These findings show that both native breeds, BAR and QFO, are characterized by high genetic variability, highlighting the importance of safeguarding their genetic variability in the context of preserving the Tunisian global sheep genetic diversity. All loci in the BAR and QFO breeds were in HWE (Table 2), with the exception of ILST087 and OarAE129, respectively. In CRO, 3 loci (Inra063, MCM527, and MAF214) departed from HWE. The $F_{\text {IS }}$ values for each population were low for BAR but relatively high for QFO and CRO, indicating a strong presence of inbreeding in these two populations. This difference in $F_{\text {IS }}$ values could be due to the morphological specificity of the BAR breed, which confers a paternity control-like system during mating. In fact, in BAR herds, mating relatives is generally avoided by shepherds by lifting the fat tail during copulation. This reproductive behavior could explain the low level of inbreeding found in BAR. This mating management is absent in QFO herds and in the CRO population (mainly derived from BAR males and QFO females with thin tails), where shepherd assistance is not required. Furthermore, exchange of rams between neighboring small breeders, practiced in the western-center of Tunisia (center of origin of CRO), probably allows for frequent mating between relatives. The relatedness among individuals $\left(f_{i j}\right)$ was considerable in BAR and CRO $(0.20 \pm 0.02)$, reflecting the within-breed diversity level (Table 2 ). Moreover, $\mathrm{f}_{\mathrm{ij}}$ detected between QFO and CRO was large (0.46), confirming the high genetic identity of these two populations. The BAR breed shares a slightly lower $\mathrm{f}_{\mathrm{ij}}$ coefficient $(0.45)$ with both QFO and CRO. The molecular coancestry coefficient between breeds reflects the genetic relationship in the founder population (Alvarez et al., 2005). Thus, the high $\mathrm{f}_{\mathrm{ij}}$ between the BAR and QFO breeds may be evidence of previous $N_{\mathrm{m}}$ between these populations in the past. Lower values of $\mathrm{f}_{\mathrm{ij}}$ were revealed by Alvarez et al. (2005) and Bozzi et al. (2009). $N_{\mathrm{m}}$ and $D_{\mathrm{A}}$ are provided in Table 3. $N_{\mathrm{m}}$ between the three populations was 
positive and considerably high. The number of migrant individuals estimated between BAR and CRO (27.47) was notably lower than between QFO and CRO (42.16), revealing dilution of BAR genes in the crossbred population.

Table 3. Nei's (1978) genetic distance $\left(D_{\mathrm{A}}\right)$, below the diagonal, and gene flow $\left(N_{\mathrm{m}}\right)$, above diagonal, between three Tunisian sheep populations.

\begin{tabular}{l|c|c|c}
\hline & BAR & QFO & CRO \\
\hline BAR & - & 34.50 & 27.47 \\
\hline QFO & 0.036 & - & 42.16 \\
\hline CRO & 0.044 & 0.034 & - \\
\hline
\end{tabular}

BAR, Barbarine breed; QFO, Queue Fine de l'Ouest breed; CRO, crossbreed (BAR x QFO).

Using random amplified polymorphic DNA (RAPD) analysis, El Hentati et al. (2013), found lower but considerable $N_{\mathrm{m}}$ values (1.31) between the BAR and QFO breeds. Both investigations of these two native breeds, using RAPD and microsatellite markers, have revealed that a level of $N_{\mathrm{m}}$ greater than one (Wright, 1931) leads to homogenize BAR and QFO breeds. Consequently, the high $N_{\mathrm{m}}$ between these two native Tunisian breeds is the main reason for the limited genetic differentiation observed between them. Very low values of $N_{\mathrm{m}}$ were revealed by Salamon et al. (2014). In the current study, Nei's $D_{A}$ was low between the studied groups, revealing that CRO is closer to QFO than to BAR (Table 3). The NJ consensus tree, based on $D_{\mathrm{A}}$ distances (Figure 1), showed a high bootstrap value (100\%) for the BAR-CRO node. Variation between populations, analyzed using AMOVA, was $0.8 \%$ between both the BAR and QFO and the BAR and CRO, while it was only $0.31 \%$ between the QFO and CRO. The majority of genetic variation $(99.38 \%)$ was found within breeds.

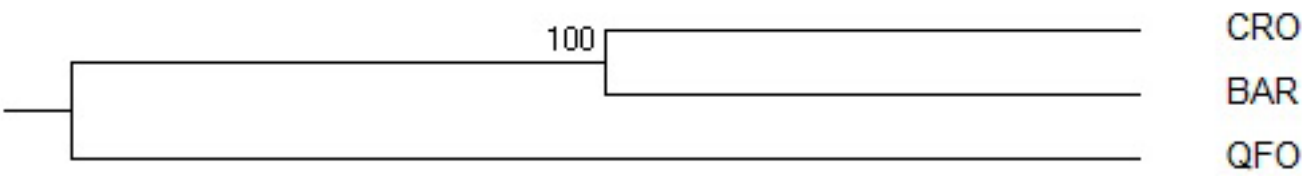

Figure 1. Neighbor-joining consensus tree showing the genetic relationship between the native Tunisian sheep breeds based on $D_{A}$ distances. BAR = Barbarine; $\mathrm{QFO}=$ Queue Fine de l'Ouest; CRO = crossbreed (BAR x QFO). Bootstrap value is indicated on the tree node.

Factorial correspondence analysis was performed including all populations and loci, and using the corresponding allele frequencies (Figure 2). The first three components explained only $6.91 \%$ of the total variation and no clear separation was found between the analyzed groups.

The optimum number of clusters, $\mathrm{K}=3$, derived using the STRUCTURE analysis is shown in Figure 3. Individuals from the analyzed breeds were split into three different clusters. Admixed individuals were differently distributed between the clusters and the average membership coefficient for BAR, QFO, and their crossbreed CRO is depicted in Table 4. The proportion of membership in the different clusters was moderate and varied among the analyzed groups. BAR exhibited the highest value $(45.7 \%)$ of membership into the third cluster (pink color in Figure 3 ) whereas QFO exhibited the highest proportion of membership (46.9\%) into the first cluster (yellow color in Figure 3). The lowest value of assignment was found for the CRO population, which showed similar proportions of membership in the three different clusters. 


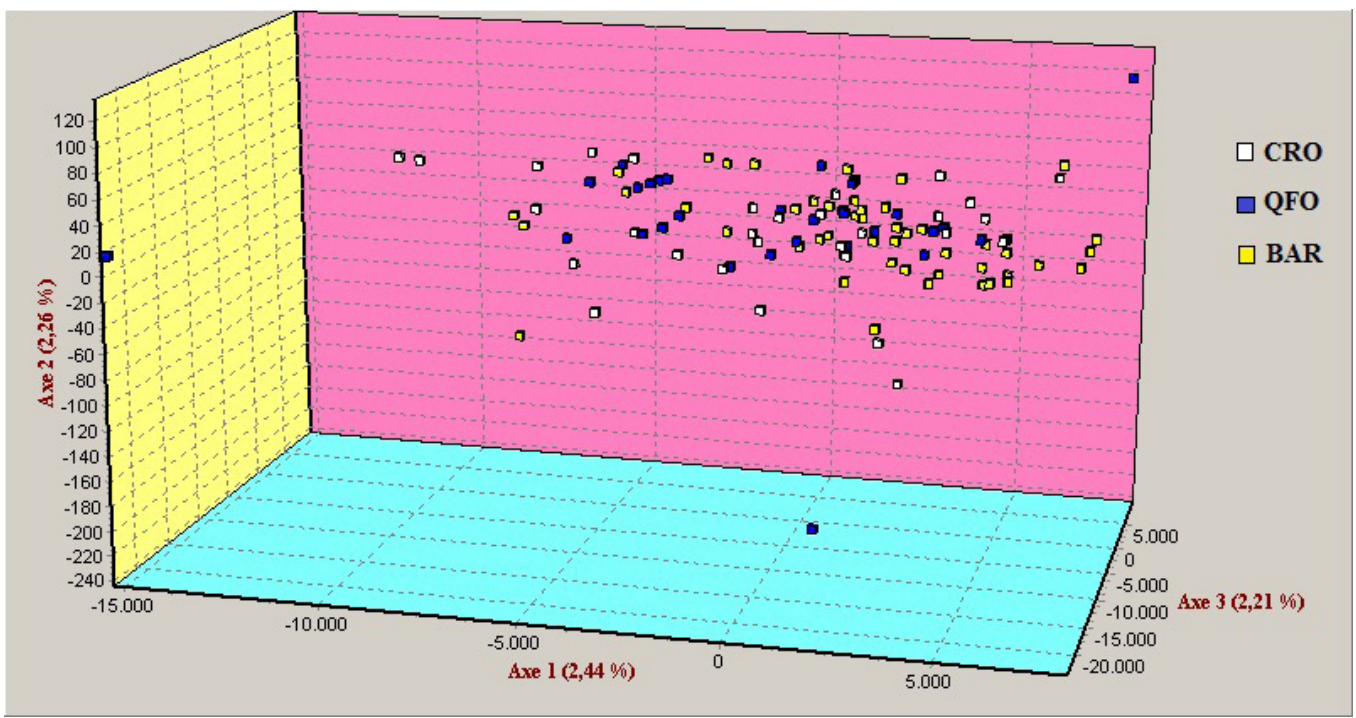

Figure 2. Spatial representation of two native Tunisian sheep breeds, Barbarine (BAR) and Queue Fine de l'Ouest (QFO), and their crossbred ( $C R O=B A R \times Q F O)$, as defined by the factorial correspondence analysis based on all microsatellite loci and corresponding allele frequencies. The first three axis explained $6.91 \%$ of the total variation; the share of each axis is indicated by the value in parentheses.

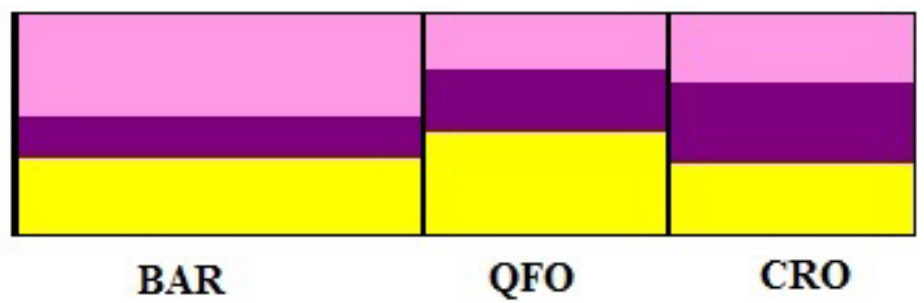

Figure 3. Estimated subdivision of three native Tunisian sheep breeds, Barbarine (BAR), Queue Fine de l'Ouest (QFO), and their crossbreed (CRO = BAR $\times$ QFO), into three clusters, inferred from STRUCTURE analysis. Mean membership of each breed to each cluster is provided in Table 4.

Table 4. Proportion of membership of each of the analyzed Tunisian sheep breeds in the 3 inferred clusters derived using the STRUCTURE software (maximal contribution in bold).

\begin{tabular}{l|c|c|c}
\hline Breed/cluster & 1 & 2 & 3 \\
\hline BAR & 0.349 & 0.194 & $\mathbf{0 . 4 5 7}$ \\
\hline QFO & $\mathbf{0 . 4 6 9}$ & 0.286 & 0.246 \\
\hline CRO & 0.324 & $\mathbf{0 . 3 8 1}$ & 0.295 \\
\hline
\end{tabular}

$\mathrm{BAR}=$ Barbarine breed; $\mathrm{QFO}=$ Queue Fine de l'Ouest breed; $\mathrm{CRO}=$ crossbreed (BAR $\times$ QFO).

This result revealed that, aside from the same pattern of miscegenation taking place in the past during the development of the BAR and QFO breeds, specific genes of these two breeds are diluted in the CRO population. It should be noted that these results are in accordance with the narrative history of sheep in Tunisia and North Africa. In fact, Phoenician and Roman monuments depict that a very long, thin-tailed breed replaced a fat-tailed breed previously brought 
by the Phoenicians approximately 400 B.C. After the miscegenation of these two sheep, a second reintroduction of a fat-tailed sheep by the Arab tribes was maintained until 900 A.D. (Sarson, 1973). Furthermore, Muigai and Hanotte (2013), summarizing the history of African sheep, indicate that the first sheep coming to North Africa from the domestication center at approximately $6500 \mathrm{BP}$ were thin-tailed, then at approximately $3000 \mathrm{BP}$, a second wave of fat-tailed sheep selected in the domestication center entered North Africa and replaced and/or were subjected to introgression with the local thin-tailed sheep. After these waves of migrations and miscegenations, isolation of each breed would have occurred. In fact, two evolution trends would have taken place depending on the new environment: a) evolution to a thin-tailed sheep in the eastern highlands of Algeria, where the fat originally stored in the tail was no longer needed and the result was the Ouled Djellal Algerian breed from which was derived the recent QFO Tunisian breed; b) In Tunisia, the evolution to the recent fat-tailed BAR breed would have occurred, especially since the last wave of sheep introduced by the Arab tribes (900 AD) from North Africa brought only fat-tailed sheep and concerned mainly Tunisia and Libya. Consequently, the fat-tail phenotype reappeared and was dominated in Tunisia, despite the presence of the thin-tailed genes in the miscegenated genetic background of the Tunisian sheep.

This situation seems to be similar to the history of the two groups of Moroccan sheep breeds, the group of the plateau and the group of Atlantic coast, where a fat-tailed breed originated from Asia has evolved to the recent thin-tailed sheep breeds of these two regions (Guessous et al., 1989). The STRUCTURE results from the current study suggest similarity of the BAR and QFO native breeds, highlighting their common genetic background. The study of Muigai and Hanotte (2013) revealed a closer relationship between the North African fat-tailed sheep and the thin-tailed West African sheep than with any of the East and South African fat-tailed sheep, which corroborates the hypothesis of a common genetic background for the fat-tailed BAR and the thin-tailed QFO Tunisian native breeds. However, in the current study, differences in the admixture distribution of the three clusters identified between BAR and QFO during the STRUCTURE analysis reveal the existence of genetic material specific to each breed (QFO has the highest proportion of membership in the first cluster and BAR has the highest proportion of membership in the third cluster), which emphasizes the uniqueness of each breed. According to the STRUCTURE analysis and the estimates of $N_{\mathrm{m}}$, which reveal high $N_{\mathrm{m}}$ between the studied populations, genetic material specific to each breed is gradually being eroded in the crossbred CRO population. Indeed, since CRO is more distant from the BAR breed than the QFO breed, and $N_{\mathrm{m}}$ between QFO and CRO is higher than $N_{\mathrm{m}}$ between BAR and CRO, the dilution of BAR genes following this crossbreeding practice has become strongly established. Thus, specific genetic characters of BAR, which are absent in QFO, especially high rusticity, adaptability to both cold and warm climates, high mothering ability, resistance to external and internal parasites, and superior meat quality, have been compromised by this crossbreeding. The situation for sheep livestock in Tunisia is therefore precarious since mutations within Tunisian production systems induced mainly by climate change, which will be warmer and drier, are in favor of breeding very adapted and rustic breeds like BAR (Ben Salem et al., 2011). This crossbreeding trend should consequently be stopped immediately to prevent a complete loss of specifically adapted genes, mainly present in the BAR breed.

\section{Conservation of indigenous Tunisian meat sheep through breeding strategy}

Characterization of the genetic variability of local breeds is one of the global priorities of scientific research and it is dictated both by the re-evaluation of practices in livestock breeding 
and by the conservation of genetic resources. In Tunisia, despite traditional quantitative genetic improvement methods of growth traits being in place for many decades, no clear genetic improvement has been obtained. In fact, despite a national strategy in red meet self-sufficiency, ovine meat imports grew from zero tons in 2003 to 1800 tons in 2012 (FAOSTAT, 2014). The contribution of sheep meat to the total supply of meat has steadily declined over the past three decades of the twentieth century [from approximately $40 \%$ in 1978 to $33 \%$ in 1986 and $25 \%$ in 1996, with an average consumption per capita decreasing from $7 \mathrm{~kg}$ in 1980 to $4 \mathrm{~kg}$ in 1996 (Hammami et al., 2007)]. The contribution of sheep meat to the total supply of meat reached $40 \%$ again during this decade and it stabilized at this level, despite efforts made to increase it. Moreover, the major socio-cultural role of using Tunisian local sheep as a sacrificial animal in the religious ceremony of "Aid al-Adha" is no longer carried out as sheep have been imported from Romania and Spain for this ceremony by the Tunisian government in the last couple of years. Consequently, complementary actions should urgently be planned in both public and private sectors to improve productive traits without losing the breed integrity and the high genetic variability found in these autochthones Tunisian breeds.

Several measures need to be taken, starting with the establishment of an adequate organizational structure of breeders and stakeholders for the implementation of policies for genetic resources, maintaining, as well as implementing, breeding goals and strategies. Subsequently, the establishment and reconstruction of a pedigree, also with the aid of molecular tools, is fundamental for the implementation of both functional and productive traits, for controlling crossbreeding, and to implement a conservation strategy.

All these actions require a strong collaboration between breeders, associations, universities, and research centers that needs to be established. Actions of these collaborators should be under national agricultural development goals, which must include Tunisian economic variables, accommodate ethics, and other social aspects of human well-being, as indicated by the FAO (2007).

The lack of information on the genetic variability and population structure of local sheep genetic resources will be a barrier for future sustainable sheep industry developments. The current study shows that microsatellite markers can be successfully used to investigate the genetic variability and structure of Tunisian local sheep breeds, providing important and useful tools for improving breeding programs of local breeds that are highly adapted to hard environmental conditions. The BAR and QFO breeds can be efficiently used for increasing the production chain if they are subject to suitable breeding programs to improve within-breed production traits in order to increase their genetic ability for both productivity and profitability. In contrast, this investigation highlighted that the BAR breed shows stronger signs of genetic erosion than the QFO breed and its gene pool is being diluted in the CRO population, which has been expanding recently. The BAR breed is numerically the most important and its products are in demand with local needs. This clearly indicates that urgent measures of conservation and sustainable management of the BAR gene pool must be undertaken.

\section{Conflicts of interest}

The authors declare no conflict of interest.

\section{ACKNOWLEDGMENTS}

The authors are grateful to the Commissariats Régionaux au Développement Agricole 
(C.R.D.A), the Office des Terres Domaniales (O.T.D.), and to the breeders for the blood sampling. Research is mainly supported by the Tunisian Ministry of Higher Education and Scientific Research.

\section{REFERENCES}

Agriculture Ministry (2006). Ministère de l'Agriculture, des ressources hydrauliques et de la pêche. General direction of studies and agricultural Developpement. Enquête sur les structures des exploitations agricoles (2004-2005), Tunisia.

Agriculture Ministry (2012). Ministère de l'Agriculture, des ressources hydrauliques et de la pêche. Direction Générale de la Production Agricole (DGPA). Rapport annuel sur l'élevage campagne 2011-2012, Tunisia.

Al-Barzinji YMS, Lababidi S, Rischkowsky B, Al-Rawi AA, et al. (2011). Assessing genetic diversity of Hamdani sheep breed in Kurdistan region of Iraq using microsatellite markers. Afr. J. Biotechnol. 10: 15109-15116. http://dx.doi.org/10.5897/ AJB10.2689

Alvarez I, Gutiérrez JP, Royo LJ, Fernández I, et al. (2005). Testing the usefulness of the molecular coancestry information to assess genetic relationships in livestock using a set of Spanish sheep breeds. J. Anim. Sci. 83: 737-744.

Baumung R, Cubric-Curik V, Schwend K, Achmann R, et al. (2006). Genetic characterisation and breed assignment in Austrian sheep breeds using microsatellite marker information. J. Anim. Breed. Genet. 123: 265-271. http://dx.doi.org/10.1111/ j.1439-0388.2006.00583.x

Bedhiaf-Romdhani S, Djemali M, Zaklouta M and Iniguez L (2008). Monitoring crossbreeding trends in native Tunisian sheep breeds. Small Rumin. Res. 74: 274-278. http://dx.doi.org/10.1016/j.smallrumres.2007.07.008

Belkhir K, Borsa P, Chikhi L, Raufaste N, et al. (1996-2004). GENETIX 4.05, logiciel sous Windows TM pour la génétique des populations. Laboratoire Génome, Populations, Interaction. Université de Montpellier II, Montpellier, France. Available at [http://www.genetix.univ-montp2.fr/genetix/intro.htm].

Ben Salem H, Lassoued N and Rekik M (2011). Merits of the fat-tailed Barbarine sheep raised in different production systems in Tunisia: digestive, productive and reproductive characteristics. Trop. Anim. Health Prod. 43: 1357-1370. http://dx.doi. org/10.1007/s11250-011-9863-8

Ben Sassi-Zaidy Y, Maretto F, Zanetti E, Hajji GM, et al. (2014a). Genetic structure and variability within and among populations of the fat-tailed Barbarine sheep breed using microsatellites markers. Afr. J. Biotechnol. 13: 44-54. http://dx.doi. org/10.5897/AJB2013.13363

Ben Sassi-Zaidy Y, Maretto F, Charfi-Cheikrouha F and Cassandro M (2014b). Genetic diversity, structure, and breed relationships in Tunisian sheep. Small Rumin. Res. 119: 52-56. http://dx.doi.org/10.1016/j.smallrumres.2014.02.005

Blackburn HD, Paiva SR, Wildeus S, Getz W, et al. (2011a). Genetic structure and diversity among sheep breeds in the United States: identification of the major gene pools. J. Anim. Sci. 89: 2336-2348. http://dx.doi.org/10.2527/jas.2010-3354

Blackburn HD, Toishibekov Y, Toishibekov M, Welsh CS, et al. (2011b). Genetic diversity of Ovis aries populations near domestication centers and in the New World. Genetica 139: 1169-1178. http://dx.doi.org/10.1007/s10709-011-9619-4

Bozzi R, Degl'Innocenti P, Rivera Diaz P, Nardi L, et al. (2009). Genetic characterization and breed assignment in five Italian sheep breeds using microsatellite markers. Small Rumin. Res. 85: 50-57. http://dx.doi.org/10.1016/.jsmallrumres.2009.07.005

Dalvit C, De Marchi M, Zanetti E and Cassandro M (2009). Genetic variation and population structure of Italian native sheep breeds undergoing in situ conservation. J. Anim. Sci. 87: 3837-3844. http://dx.doi.org/10.2527/jas.2008-1682

Dieringer D and Schlötterer C (2003). MICROSATELLITE ANALYSER (MSA): a platform independent analysis tool for large microsatellite data sets. Mol. Ecol. Notes 3: 167-169. http://dx.doi.org/10.1046/j.1471-8286.2003.00351.x

El Hentati H, Ben Hamouda M and Chriki A (2013). Genetic differentiation and gene flow between four Tunisian sheep populations (Ovis aries) using random amplified polymorphic DNA-polymerase chain reaction (RAPD-PCR) analysis. Res. Opin. Anim. Vet. Sci. 3: 149-152.

Excoffier L, Laval G and Schneider S (2005). Arlequin (version 3.0): an integrated software package for population genetics data analysis. Evol. Bioinform. Online 1: 47-50.

FAO (2007). Genetic improvement methods to support sustainable utilization.In: The state of the world's animal genetic resources for food and agriculture. Rome, 381-427.

FAO (2011). Molecular genetic characterization of animal genetic resources. FAO Animal Production and Health Guidelines. No. 9. Rome, 72-73.

FAOSTAT (2014). Food and agriculture organization of the United Nations. Statistics Division. http://faostat3.fao.org.Accessed Febrary 14, 2015.

Felsenstein J (1989). PHYLIP-phylogeny inference package. Cladistics 5: 164-166 Available at http://evolution.gs.washington. edu/phylip.html.

Ferreira JSB, Paiva SR, Silva EC, McManus CM, et al. (2014). Genetic diversity and population structure of different varieties of Morada Nova hair sheep from Brazil. Genet. Mol. Res. 13: 2480-2490. http://dx.doi.org/10.4238/2014.April.3.20

Genetics and Molecular Research 15 (1): gmr.15017059 
Glaubitz JC (2004). Convert: a user-friendly program to reformat diploid genotypic data for commonly used population genetic software packages. Mol. Ecol. Notes 4: 309-310. http://dx.doi.org/10.1111/j.1471-8286.2004.00597.x

Guessous F, Boujenane I, Bourfia M and Narjisse H (1989). Sheep in Morocco. In: Small Ruminant in the Near East. Volume III: North Africa. FAO Animal Production and Health Paper, Rome, 49-95.

Gutiérrez JP, Royo LJ, Alvarez I and Goyache F (2005). MolKin v2.0: a computer program for genetic analysis of populations using molecular coancestry information. J. Hered. 96: 718-721. http://dx.doi.org/10.1093/jhered/esi118

Hammami M, Soltani E and Snoussi S (2007). Importance de la filière viande ovine en Tunisie: stratégies des acteurs (cas de la région de Zaghouan). New Medit 6: 14-22.

Kunene NW, Ceccobelli S, Di Lorenzo P, Hlophe SR, et al. (2014). Genetic diversity in four populations of Nguni (Zulu) sheep assessed by microsatellite analysis. Ital. J. Anim. Sci. 13: 76-82. http://dx.doi.org/10.4081/ijas.2014.3083

Mason IL (1967). The sheep breeds of the mediterranean. FAO and Commonwealth Agricultural Bureaux, Farnham Royal.

Muigai AWT and Hanotte O (2013). The origin of African sheep: archaeological and genetic perspectives. Afr. Archaeol. Rev. 30: 39-50. http://dx.doi.org/10.1007/s10437-013-9129-0

Mukhongo DM, Mwai O, Tapio M and Muigai A (2014). Genetic diversity and population structure of the indigenous sheep in Kenya based on microsatellite analysis: implications for their conservation. Livest. Sci. 5: 65-78.

Nei M (1978). Estimation of average heterozygosity and genetic distance from a small number of individuals. Genetics 89 : 583-590.

OEP (2009). Indicateurs du secteur de l'élevage produits du système d'information de l'OEP (Office de l'Elevage et des Paturages). Résultats du contrôle des performances 2009, Tunisia.

Pritchard JK, Stephens M and Donnelly P (2000). Inference of population structure using multilocus genotype data. Genetics 155: 945-959.

Raymond M and Rousset F (1995). GENEPOP (version 1.2): population genetics software for exact tests and ecumenicism. J. Hered. 86: 248-249.

Rosenberg NA (2004). DISTRUCT: a program for the graphical display of population structure. Mol. Ecol. Notes 4: $137-138$. http://dx.doi.org/10.1046/j.1471-8286.2003.00566.x

Salamon D, Gutierrez-Gil B, Arranz JJ, Barreta J, et al. (2014). Genetic diversity and differentiation of 12 eastern Adriatic and western Dinaric native sheep breeds using microsatellites. Animal 8: 200-207. http://dx.doi.org/10.1017/ $\underline{\mathrm{S} 1751731113002243}$

Sarson M (1973). Les ovins dans l'antiquité d'après les vestiges phéniciens et romains en Tunisie et en Algérie. DocumenttechniqueNo. 65. Institut National de la Recherche Agronomique, Paris.

Soma P, Kotze A, Grobler JP and Van Wyk JB (2012). South African sheep breeds: population genetic structure and conservation implications. Small Rumin. Res. 103: 112-119. http://dx.doi.org/10.1016/j.smallrumres.2011.09.041

Souza CA, Paiva SR, McManus CM, Azevedo HC, et al. (2012). Genetic diversity and assessment of 23 microsatellite markers for parentage testing of Santa Inês hair sheep in Brazil. Genet. Mol. Res. 11: 1217-1229. http://dx.doi.org/10.4238/2012. May.8.4

Tamura K, Peterson D, Peterson N, Stecher G, et al. (2011). MEGA5: molecular evolutionary genetics analysis using maximum likelihood, evolutionary distance, and maximum parsimony methods. Mol. Biol. Evol. 28: 2731-2739. http://dx.doi. org/10.1093/molbev/msr121

Weir BS and Cockerham CC (1984). Estimating F-Statistics for the analysis of population structure. Evolution 38: $1358-1370$. http://dx.doi.org/10.2307/2408641

Wright S (1931). Evolution in Mendelian populations. Genetics 16: 97-159. 